\section{EL PATRIMONIO CULTURAL Y EL SISTEMA EMOCIONAL: UN ESTADO DE LA CUESTIÓN DESDE LA DIDÁCTICA}

\author{
Joan Santacana Mestre \\ Universidad de Barcelona \\ ORCID iD: https://orcid.org/0000-0003-4593-2517 \\ jsantacana@ub.edu \\ Tània Martínez Gil \\ Universidad de Barcelona \\ ORCID iD: https://orcid.org/0000-0002-6198-1063 \\ tania.martinezgil@ub.edu
}

\section{THE CULTURAL HERITAGE AND THE EMOTIONAL SYSTEM: AN APPROACH FROM TEACHING}

Cómo citar este artículo/Citation: Santacana Mestre, J. y Martínez Gil, T. (2018). El patrimonio cultural y el sistema emocional: un estado de la cuestión desde la didáctica. Arbor, 194 (788): a446. https://doi.org/10.3989/arbor.2018.788n2006
Copyright: (c) 2018 CSIC. Este es un artículo de acceso abierto distribuido bajo los términos de la licencia de uso y distribución Creative Commons Reconocimiento 4.0 Internacional (CC BY 4.0).

Recibido: 6 marzo 2015. Aceptado: 8 febrero 2016.

RESUMEN: El artículo analiza el factor emocional y su relación con el patrimonio cultural. Asimismo, se plantea cómo este factor es fundamental y en ocasiones decisivo en relación con la didáctica y la difusión de elementos patrimoniales. Partiendo de modelos patrimoniales existentes se investiga el peso de factores como la sorpresa, la empatía y la identidad, resumiendo las últimas investigaciones que en este sentido hemos realizado en el seno de nuestro grupo de investigación. Los análisis se basan en ejemplos de patrimonio arqueológico, artístico y arquitectónico.

PALABRAS CLAVE: educación patrimonial; inteligencia emocional; patrimonio cultural; didáctica; empatía; aprendizaje.

ABSTRACT: This article analyses the emotional factor and its connections with cultural heritage. It also considers how this factor is fundamental and sometimes decisive for the didactics and the dissemination of heritage elements. Based on existing heritage models, the weight of aspects like surprise, empathy or identity is studied. We also summarise the latest findings in the field made by our research group. The analysis is based on examples taken from archaeological, artistic and architectonicmonumental heritage.

KEYWORDS: heritage education; emotional intelligence; cultural heritage; teaching; empathy; learning. 


\section{LOS PARADIGMAS EMOCIONALES DEL PATRIMONIO}

Analizar el papel del sistema emocional en nuestra percepción del patrimonio no es un tema fácil; pero si ello se quiere plantear desde la didáctica, es decir desde la óptica del aprendizaje, es mucho más complejo.

Es casi obligado, en el momento de trazar el estado de la cuestión, referirse a lo que entendemos por emoción; naturalmente lo primero que hay que decir es que se trata de un estado afectivo que transforma nuestro equilibrio psico-físico de una forma transitoria pero que puede llegar a ser intensa. Este estado de equilibrio puede ser afectado por elementos externos, los cuales son la causa de muchas emociones, aun cuando puede haber causas internas desencadenantes de la emoción. Veamos, antes de analizar como actúan las emociones en los procesos de aprendizaje, algunos ejemplos característicos:

Ejemplo 1. La visita al campo de concentración nazi de Ravensbrück, cerca de Fürstenberg, a casi un centenar de kilómetros de Berlín puede provocar reacciones distintas entre los visitantes, a veces visibles. Se trataba de un campo dedicado a acoger a mujeres, al que se le unió luego una sección de chicas jóvenes y niñas. El campo desarrolló a su alrededor un recinto industrial con talleres de producción (confecciones básicamente) y, desde 1942, la empresa Siemens edificó junto al campo una gran cantidad de naves industriales para fabricar armamentos que, obviamente, recaían sobre las reclusas. Se calcula que más de cien mil mujeres y un millar de niñas pasaron por este campo, donde se instalaron cámaras de gas y se calcula que un total de 92.000 personas fueron asesinadas en Ravensbrück.

Ante este enorme complejo patrimonial muchas personas reaccionan con un sentimiento de cólera, de indignación y enojo. Esta reacción es típicamente emocional; lo mismo ocurre cuando se visitan museos como el Yad Vashem de Jerusalén en memoria del holocausto (Gutterman y Shalev, 2008, pp. 22-25) o el Jüdisches Museum de Berlín. Por lo tanto, podemos afirmar que hay emociones que están relacionadas con la cólera o la indignación.

Ejemplo 2. Muy distinta es la reacción de muchos visitantes que visitan el famoso castillo de Neuschwanstein, cerca de Fusen, en Baviera. Se trata de una extraña construcción que se edificó por orden del rey Luis II en 1869, en una época en que los castillos no tenían ya ninguna utilidad; fue una gran fantasía romántica, en la que el monarca quería revivir una época absolutamente periclitada. Se trataba de un castillo ideal, fantástico, casi de leyenda. Además, la mole se halla enclavada sobre el desfiladero del Pöllat, en plenos Alpes, un paisaje realmente de ensueño. En definitiva, una escenografía para el placer estético y paisajístico (Burillo et al., 1988, pp. 1061-1063). Pero ¿qué reacciones produce esta obra cuando se visita? Hoy es uno de los monumentos más visitados de Alemania y, a pesar de las incomodidades que ello provoca, las visitantes suelen tener una experiencia alegre, con un sentimiento de extravagancia y de capricho. Y todo ello es una reacción también emocional.

Ejemplo 3. Hay veces que el deleite ante el patrimonio produce un cierto miedo o inquietud. Cuando el turista se adentra en la red de catacumbas romanas que se extienden bajo la Via Apia, de unos 170 kilómetros de longitud, con más de medio millón de tumbas, el descenso, en varios niveles puede llegar a sobrecoger (Fink y Asamer, 1997). El sistema de túneles subterráneos, excavados en la toba, impresiona y hay personas que tienen verdadero pánico a causa de la claustrofobia que producen. Téngase en cuenta que hay algunas de estas galerías que tienen más de veinte kilómetros subterráneos laberínticos, como las de San Calixto, o las de San Sebastián con más de 12 kilómetros El miedo, la ansiedad, el desasosiego son también una reacción emocional.

Ejemplo 4. También existe en algunas ocasiones la sensación de tristeza, casi de aflicción, mezclada con cierta nostalgia. Esto es lo que pueden producir unas ruinas del pasado que fueron majestuosas y hoy solo conservan el esqueleto; es el caso de conjuntos mayas como el de Chichén Itzá, en el centro de la Península de Yucatán (Lavallé, Michelet y Ocampo, 1988, pp. 152-153). Para una parte de la población de origen maya estas ruinas son la evidencia del genocidio que sufrieron sus antepasados; ellos todavía hablan una lengua maya y los conjuntos monumentales les pueden provocar sensación de tristeza quizás mezclada con la nostalgia del pasado.

Ejemplo 5. A veces el patrimonio puede ser contemplado con un inmenso placer, con sensaciones de afinidad con el artista o con la obra, casi con devoción ante la misma. Estas reacciones son perceptibles a veces en grandes obras mitificadas por la cultura; es el caso del Guernica de Pablo Picasso, expuesto hoy en el Museo Reina Sofía de Madrid o de los Fusilamientos de la Moncloa de Goya, en el Museo del Prado. ¿Cuántas obras de esta pinacoteca están rodeadas de sentimientos de placer, casi de amor?

Ejemplo 6. Muchas veces, la reacción ante el patrimonio cultural es de sorpresa, casi de asombro o de 
estupefacción. Esta es la reacción que suelen tener los viajeros que penetran a través del siq o desfiladero de Petra. La antigua capital del Reino Nabateo está excavada en la roca, casi esculpida en ella. Se trata de una ciudad cuyo origen se remonta al siglo VIII a. C. pero que prosperó especialmente dos siglos después, bajo los pueblos nabateos. La razón de ello es que la ciudad estaba situada en plena ruta del incienso y de las especias entre Arabia y el Mediterráneo. La sorpresa no desaparece después del primer impacto visual, sino que se va acumulando a medida que nos adentramos en el interior del valle, que en realidad es enorme, ya que se extiende desde el mar Muerto al Golfo de Aqaba.

Ejemplo 7. En ocasiones el patrimonio provoca sentimientos confusos de pena, de remordimiento, casi de culpa o de vergüenza. ¿Qué experimentan muchos ciudadanos centroeuropeos hoy cuando visitan complejos como la tristemente denominada Topografía del Terror de Berlín? (Nachama, 2008, pp. 5-9). El recorrido por lo que fue el centro de poder nazi en la capital del III Reich, por los sótanos hoy visibles de los calabozos de la Gestapo produce ciertamente una sensación de vergüenza en mucha gente. Piensan: ¿cómo pudieron nuestros padres y abuelos llegar a esto?

Ejemplo 8. En Palermo, bajo el monasterio de la Orden de los Capuchinos menores, los monjes, desde el siglo XVI, excavaron un cementerio subterráneo. Los cadáveres se sometían a deshidratación y se trataban con ácido acético; algunos se embalsamaban, se les volvía a colocar sus propias ropas y se dejaban así expuestos. Aun cuando en sus orígenes estaban destinadas únicamente al sepelio de los frailes, con el paso del tiempo, familias respetables de Palermo pedían autorización para ser enterradas en este lugar, siguiendo estas mismas pautas. El resultado es que debajo del convento hay hoy más de ocho mil cadáveres, muchos de los cuales están momificados y se exhiben vestidos e incluso de pie. Hay desde niños hasta médicos, diplomáticos, monjes, hombres y mujeres de todas las edades y profesiones. ¿Qué tipo de emoción produce esta visita turística en mucha gente? La reacción a veces es de asco, de repulsión, casi de un sentimiento de aberración. Y esto es también una emoción.

Estos ejemplos se presentan como paradigmáticos de lo que puede ser el complejo sistema emocional en el tratamiento del patrimonio; naturalmente, las emociones nunca suelen ir solas y normalmente se nos presenten asociadas; es frecuente asociar el asco con el remordimiento; la sorpresa puede asociarse con el miedo o con el placer y el amor puede asociarse a muchas otras emociones, como admiración, piedad, etc.

\section{LAS EMOCIONES Y LA MOTIVACIÓN: DOS CONCEPTOS INTERRELACIONADOS}

No es este el lugar para discutir las causas complejas de las emociones ni si, como propuso Robert Zanjonc (1923-2008), los sistemas cognitivos y los afectivos son independientes o interdependientes. No podemos hoy discutir si las emociones pueden surgir sin elementos de conocimiento o cognición (Zanjonc y Hazel, 1982, pp. 123-131). Tampoco existen pruebas fehacientes de que la cognición sea una de las condiciones sine qua non para las emociones, como pretenden otros autores. Lo que nos importa para nuestro análisis no es tanto la génesis de las emociones sino su relación con el aprendizaje y la de este con la didáctica del patrimonio.

En este sentido, resulta interesante la conocida ley de Yerkes-Dodson (Yerkes y Dodson, 1908, pp. 459485) que ya a principios del siglo pasado pusieron de manifiesto -si no es que demostraron- que hay una relación clara entre la excitación emocional y el aprendizaje; en realidad establecieron que cuanta menos actividad emocional existe, también se produce menos aprendizaje y a la inversa: "cuando se incrementa la actividad emocional se eleva el aprendizaje". Esta ley, en su expresión matemática, correlaciona el cociente intelectual y el emocional de modo que su representación gráfica es una $U$ invertida, es decir, a más emoción hay más aprendizaje, pero se llega a un punto óptimo o máximo a partir del cual, si sigue aumentando la emoción, decrece el aprendizaje.

Un ejemplo de aplicación de esta ley en el campo que nos ocupa, el del patrimonio cultural, es que cuando visitamos un equipamiento museístico que nos genera mucho interés, que nos emociona mucho por la razón que fuere, nuestra excitación va en aumento y el proceso de aprendizaje está activado al máximo, pero llega un momento en el cual, por cansancio o por cualquier otro factor, cuando más aumenta la excitación, el nivel de saturación es tan elevado que decae. Por lo tanto, no hay que esperar que siempre se mantenga igual el estado emocional; es como el sentimiento de alegría o de pena, que no se pueden mantener indefinidamente; ello solo se produce en estados psicopatológicos.

De todo ello se desprende la importancia de las emociones y de la educación emocional. Los grandes teóricos de la educación del siglo pasado, tales como Ovide Decroly y María Montessori, ya creyeron que el ser humano nace con un gran potencial que había que potenciar y desarrollar. Por ello la función más importante del educador es acompañar a las personas, en 
cualquier edad de la vida, en su proceso de aprendizaje. Para ello fundamentaron lo que se ha denominado didáctica del objeto, ya que la observación estaba en el centro de la escuela y los objetos, como elementos concretos, son observables (Santacana y Llonch, 2012, pp. 23-30). La educación emocional, en la medida en que incita la motivación, produce en el individuo una alta dosis de satisfacción y de felicidad. No es pues exagerado afirmar que la educación exige emociones; poco se puede construir entre individuos inertes a toda emoción. Por ello podemos afirmar que el patrimonio es una herramienta educativa ya que contiene un alto potencial de emotividad.

\section{EL PATRIMONIO CULTURAL Y LAS EMOCIONES}

Hay personas que se emocionan ante los objetos muy antiguos; la remota antigüedad de un objeto prehistórico, el pisar un yacimiento arqueológico en el cual vivieron homínidos o humanos de nuestra especie hace millones o miles de años les provoca una extraña sensación, como si el tiempo se precipitara encima de ellos, y no hay nada de malo ni de enfermizo en esta actitud porque es una emoción lícita, desencadenada en nuestro cerebro cuando tenemos conciencia temporal. Otras personas se sienten emocionadas al pisar escenarios del pasado en los cuales ocurrieron cosas extraordinarias. Así les conmueve el Salón de los Espejos de Versalles o los campos de Batalla de guerras remotas; y esta emoción, derivada se sus lecturas, del visionado de películas o de escuchar relatos es una emoción innegable, humana, y nada tiene de extemporáneo o extraño (Martínez y Santacana, 2013).

También hay personas que se estremecen cuando ven objetos o escenarios de cosas que ocurrieron en su infancia o en su juventud. El recuerdo brota en su mente y humedece sus ojos. Nada más propio de la mente humana que emocionarnos por los recuerdos de la infancia o de la juventud. Tampoco eso es ajeno al ser humano.

Finalmente, hay personas que, ante una obra de arte, sea un aria de ópera, una canción de los Beatles, un poema de Baudelaire o una pintura de Van Gogh, se quedan extasiados, en el fondo emocionados: la belleza les atrae irremisiblemente.

Frente a todos ellos surgen también individuos que manifiestan que ellos son personas lógicas, racionales, que saben dejar las emociones a un lado y examinan la realidad con objetividad. Con esta afirmación suelen querer decir que la razón y la emoción son dos elementos antagónicos. Sin embargo, la neurociencia desenmascara esta falacia; en realidad, la interacción entre la parte del cerebro encargada de las emociones -la amígdala- y la zona en donde se nucleariza lo que llamamos, sin mucha razón, pensamiento racional -el córtex cerebral- es continua y sus ataduras son muy complejas. Por otra parte, hay razones para creer que existen muchas más vías que van desde la amígdala -emociones- al córtex -razonamiento-que a la inversa. Por ello, suelen ser las emociones las que influyen sobre la razón y no al contrario, o en todo caso es más fácil esta relación que la inversa. Dicho con otras palabras, también necesitamos "el corazón" para pensar y para emitir juicios (Ledoux, 1999). A veces parece como si una reacción emocional ante el arte o ante el patrimonio no fuera propia de personas cultas; por ello las emociones a veces se esconden o se procuran aminorar. Sin embargo, nada más humano, nada más necesario que el sistema emocional para gozar del patrimonio cultural. Todas las reacciones emocionales que hemos descrito son lícitas y no tienen nada de extraño. No hay razones erróneas para que algo nos emocione; en realidad hay prejuicios, razones erróneas que nos impiden emocionarnos ante determinados elementos patrimoniales; el desconocimiento del objeto patrimonial o la falta de vivencias personales pueden ser factores que contribuyen a yugular o impedir el desarrollo emocional ante el arte o ante cualquier elemento del patrimonio cultural (Martínez, 2014).

El papel de las emociones ante el patrimonio resulta especialmente evidente cuando nos referimos al patrimonio inmaterial, que es el que está en la cabeza de las personas; sabemos un tipo de baile porque está interiorizado en nosotros; conocemos una melodía porque está almacenada en el recuerdo. Por lo tanto, cuando percibimos un recuerdo, un lugar, o a veces un objeto que ha significado algo o que es importante para nosotros, nuestra atención se altera, aumenta, y suele activar redes asociativas muy relevantes de nuestra memoria. Todo esto no es otra cosa que un conjunto de reacciones emotivas. $Y$ nuestro sistema emocional "es la guía que da luz e ilumina todos nuestros planes [...]. La emoción es el ingrediente que permite el encendido de la conducta" (Mora, 2009, pp. 155-156). Normalmente nuestras acciones e incluso nuestros aprendizajes están sujetos a las emociones; hemos planteado ya que poco o nada aprendemos sin la emoción que nos motiva, sin que tenga un significado para nuestra mente. Hoy sabemos que todo pasa por el filtro emocional. Sin embargo, el ser humano necesita siempre de otros seres humanos para mantener vivo el fuego emocional; pocos se emocionan mirando a un patinador o patinadora desde el tele- 
visor de su casa en completa soledad; sin embargo, en una grada de la pista, junto con gente a nuestro lado que vive el mismo momento, el desencadenante de las emociones es mucho más fácil. Las emociones son como un fuego que se aviva en contacto con otros seres humanos. El patrimonio cultural inmaterial, por lo que tiene de colectivo, de colaborativo, porque se conserva y almacena únicamente en la mente, tiene un alto componente emocional. Hay periodos en la vida en los cuales la construcción del sistema emocional es más importante que en otros; nos referimos a la infancia y a la adolescencia. Las emociones construidas durante la infancia permanecen para siempre, cuando revivimos fiestas tradicionales o familiares asociadas a la infancia nuestro sistema emocional reacciona y en ocasiones nos genera un placer y una alegría indescriptibles, mientras que en otros casos nos genera soledad, tristeza o desazón. La razón de ello es que "la información ambiental" moldeó la parte emocional de nuestro cerebro. Igual ocurre con etapas de la adolescencia, cuando despiertan tantos sentimientos nuevos y desconocidos en las personas; estos sentimientos y emociones -el primer beso, el primer amor... etc.- se reviven emocionalmente muchos años después precisamente porque nos revierten a una juventud temprana. El patrimonio inmaterial, en la medida que es forjador de emociones, tiene también este poder de hacer revivir sensaciones, alegrías, miedos, placer o dolor con más fuerza que cualquier otro tipo de patrimonio.

Además, el sistema emocional que activa el patrimonio inmaterial es también para muchas personas un sistema de recompensas para el cerebro; casi no hay ninguna actividad humana que como resultado último no pretenda hallar alguna recompensa, bien sea esta de tipo consumatorio, como la comida, la bebida o el sexo, o bien de tipo lúdico, el juego, o bien del tipo que llamamos espiritual, es decir, la satisfacción de resolver un problema matemático o de experimentar una sensación agradable a través del arte, de la música o de la religión. Incluso los actos más altruistas del ser humano buscan una recompensa, lo que se suele decir "el sentirse bien", el placer tras la "buena obra"; es similar al placer del atleta después del estado de agotamiento, cuando ha ganado la carrera. Al final de todos estos caminos se hallan los mecanismos emocionales de nuestro cerebro, sus sistemas de recompensa por lo hecho, por lo vivido o por lo descubierto (Martínez, 2014).

Cuando se quiebra el sistema emocional de recompensa aparece la apatía, la depresión, la obsesión para terminar con la vida. Esta digresión sobre las emociones puede parecer superflua y sin embargo es lo más importante para comprender las funciones del patrimonio cultural inmaterial. Ye hemos visto que "la relación entre las emociones y la motivación es muy íntima, ya que se trata de una experiencia presente en cualquier actividad que posee las dos principales características de la conducta motivada: dirección e intensidad" (Choliz, 2005, p. 3).

Cualquier conducta, cuando está impulsada por emociones, se realiza de forma más intensa, más vigorosa y con más ímpetu. Por ello, cuando el patrimonio cultural inmaterial está cargado de emoción, está asegurado su mantenimiento. Aquí hay una reacción biyectiva, mediante la cual las emociones estimulan la motivación y la motivación desencadena emociones; son dos caras de la misma moneda. Veamos a continuación un ejemplo: imaginemos que participamos en un ritual colectivo que nos produce sensación de felicidad. En este estado todos los estímulos ambientales, todo lo que está a nuestro alrededor lo interpretamos positivamente; este estado facilita además nuestra empatía, por ello seremos más proclives a conductas altruistas; todo lo que ocurra a nuestro alrededor lo vamos a recordar durante mucho más tiempo y tendremos mucha más facilidad para comprenderlo. Todo ello favorece las relaciones interpersonales, y todo junto nos proporciona una sensación placentera, de bienestar, que aumenta incluso nuestra autoestima y nuestra autoconfianza (Choliz, 2005, pp. 10-11).

Todo esto puede ocurrir en multitud de rituales y eventos. En la Lista de Patrimonio Inmaterial de la UNESCO hay una peregrinación anual al mausoleo de Sidi “Abd el Qader Ben Mohammed, conocido como Sidi Cheikh ${ }^{1}$. Se halla enterrado en Al Abiodh Sidi Cheikh en Argelia. El último jueves de junio se inician las celebraciones religiosas en honor a este fundador de la hermandad sufí. Esta peregrinación está organizada por los grupos nómadas de la región, todos ellos sufís. La peregrinación significa una renovación de los vínculos y las alianzas entre los miembros de la hermandad; los valores comunitarios se refuerzan, como la hospitalidad, las plegarias a Sidi Cheikh, la recitación del sagrado Corán y todo ello va acompañado de bailes, competiciones de esgrima y concursos ecuestres con centenares de jinetes. Mucha gente se emociona viendo los caballos correr y competir; hay una gran alegría entre los mayores porque ven cómo los conocimientos espirituales se aprenden y transmiten mediante estas prácticas y todos se sienten más altruistas, se establecen nuevas amistades, se conciertan 
alianzas y todo ello son funciones de la peregrinación. Sin la emoción, nada tendría sentido y es la emoción la que los motiva a todos (Santacana y Llonch, 2015; Unesco, 2013). En otras ocasiones, el desencadenante de emociones no es necesariamente una fiesta o un ritual; en Lituania hay una tradición que se conoce con Las cruces $^{2}$. Fabrican cruces y las colocan en caminos, montañas, cementerios o casas y se asociaba a las fiestas de las cosechas en los países bálticos; a menudo eran bendecidas por el sacerdote y adquirían un valor sagrado. Con la dominación rusa en el siglo XIX y la difusión de la religión ortodoxa frente a la católica latina, las cruces fueron un símbolo de identidad en Lituania; después de la dominación soviética, este simbolismo se reforzó y se convirtió en un acto de resistencia a los ocupantes. Las autoridades las prohibían y las retiraban, y pese a ello la gente les respondía multiplicándolas. Fueron quemadas muchas veces, las autoridades soviéticas establecieron en la colina un vertedero para disuadir a la gente, pero no pudieron eliminarlas. Incluso se proyectó construir una gran presa para inundarlo todo. Hoy se estima que en esta sola colina hay más de 100.000 cruces. Por ello hoy han adquirido un simbolismo que va más allá del puramente religioso ya que muchos lituanos las asocian a su lucha por la libertad. La tradición de las cruces implica no solo fabricarlas, esculpiendo imágenes de madera, sino también pintarlas y mantenerlas. Se trata de un arte anónimo, en donde no figura el autor, ni su nombre. No se enseña en las escuelas pero la gente lo mantiene. La capacidad emotiva de este patrimonio es muy alta, ya que para mucha gente significa su voluntad de resistir la opresión, su férrea decisión de mantener la identidad lituana por encima de las imposiciones de un estado, el ruso o el soviético, con el cual no se sintieron jamás identificados. Por esto es hoy un importante y emotivo patrimonio inmaterial (Santacana y Llonch, 2015). Las cruces lituanas recuerdan las ideas de Harry Browne (1933-2006) cuando escribió que "la felicidad no es un coche nuevo, fama, riqueza o incluso una manta caliente. Eso son cosas. La felicidad es una emoción [ ]" (Mora, 2009, p. 136).

\section{LOS FACTORES EMOCIONALES Y SU INFLUENCIA EN EL PROCESO DE APRENDIZAJE BASADO EN EL USO DEL PATRIMONIO: LA EMPATÍA Y LA SORPRESA COMO FACTORES CLAVES}

Si el patrimonio cultural -tanto material como inmaterial- tiene un fuerte componente emotivo, es necesario ahora plantear hasta qué punto la ley de YerkesDodson es aplicable a este campo. Para ello, y como ejemplo, nos remitiremos a uno de los trabajos realiza- do en el seno de nuestro grupo de investigación y que utilizó como "banco de pruebas" el monasterio tarraconense de Santa Maria de Poblet. Se trata de un monasterio cisterciense, fundado en el siglo XII y que pese a los procesos desamortizadores hoy sigue manteniendo una comunidad religiosa. Además de las características propias de la orden del Císter, este monasterio es el panteón real de los monarcas de la Corona de Aragón y constituye uno de los grandes conjuntos monumentales de la Edad Media. Una parte de la investigación consistió en diseñar diversas estrategias educativas en el entorno del monasterio, para posteriormente ser analizadas y evaluadas por parte de grupos de jóvenes maestros de educación primaria. Para la evaluación se emplearon metodologías cuantitativas y cualitativas, siendo la técnica del focus group la herramienta principal para la obtención de resultados.

Esta técnica cualitativa está ampliamente difundida en diversos ámbitos de la investigación educativa, así como en otras disciplinas tales como la sociología o la misma psicología (Puchta y Potter, 2004; Gutiérrez, 2011). El factor común en el focus group o también denominado técnica de grupos de discusión consiste en reunir a grupos reducidos de personas para indagar acerca de sus percepciones, sus opiniones, actitudes o reacciones frente a un tema o problema y, en el caso que nos ocupa, una situación problemática. Por ello, a lo largo de los distintos debates grupales se formularon a los participantes un conjunto de preguntas ligadas a los objetivos y las hipótesis del diseño didáctico para finalmente hacerles posicionar respecto a cuál de las actividades les había gustado más; en realidad se quería valorar el concepto de atractividad de cada una de las actividades. El primer resultado que apareció claramente definido fue que la interactividad mental y la sorpresa eran dos factores fundamentales de la atractividad. También había una relación clara entre atracción y el placer que conlleva el propio aprendizaje: la conciencia del aprendizaje. En muchos casos se reflejaba la relación clara entre "haberlo vivido" y el propio aprendizaje. Pero las actividades que fueron más atractivas y que se valoraron mejor fueron aquellas que se relacionaban con la capacidad empática. La capacidad de ponerse en la piel del otro fue el factor más destacado por los informantes y las actividades que lo propiciaban las mejor valoradas. Naturalmente para ello era necesario conocer muchos detalles, ver muchos objetos del otro y conocer a fondo la situación que se dio en el pasado. Probablemente es este factor emocional de la empatía el más importante de los que se pudieron valorar y medir con la investigación (Martínez, 2014). 


\section{CONCLUSIONES MÁS RELEVANTES}

El modelo resultante de la investigación se puede esquematizar mediante círculos concéntricos en los que se colocan los factores de atractividad y los recursos utilizados, y en los que se observa cómo de los cuatro factores que intervienen (empatía, interacción, sorpresa y variedad), tres son de carácter emocional (Figura 1).

Tan solo un factor es distinto, y es el que se refiere a la variedad. En efecto, a lo largo de la investigación emergió este factor, que inicialmente no estaba previsto y que fue el de la variedad de recursos utilizados para interpretar el patrimonio. De todos los empleados fueron destacados en la evaluación el uso de objetos (didáctica del objeto), el papel del educador, los recursos teatrales, tales como la aparición de actores y actrices en el transcurso de las experimentaciones, y el uso de diversas maletas didácticas o kits móviles en algunas actividades.

Como puede verse, los resultados de la investigación, modesta en cuanto a los recursos, son relevantes en cuanto a los resultados. Quisiéramos resaltar dos elementos fundamentales en el sistema emocional humano y que aquí sobresalen: la empatía y la sorpresa. En efecto, la clave que nos permite acceder a las emociones de los demás -radica en la capacidad de captar los mensajes no verbales-, que son fundamentalmente visuales (Goleman, 2008, p. 168). En este aspecto las teatralizaciones, cuando se realizan con cierto rigor, riqueza indumentaria o la presencia de elementos originales, cumplen estas funciones. Por otra parte, hay que recordar que los fundamentos de la empatía se hallan presentes en la mayoría de los humanos desde la infancia y, por lo tanto, los recursos de tipo empático se pueden utilizar en todas las edades de la vida. Por ello Goleman (2008, p. 170) afirma, apoyándose en trabajos previos de Martin L. Hoffman, que la psicología evolutiva ha demostrado cómo incluso los bebés experimentan angustias empáticas antes incluso de ser conscientes de su existencia. De hecho, toda relación que implique adquirir la capacidad de experimentar el estado subjetivo de los demás, ya fuere sintonizando con sus intenciones o compartiendo un deseo, es una manifestación de empatía. Por lo tanto, comprender el pasado solo es posible mediante importantes dosis de empatía, y el conocimiento y aprendizaje de la historia a través del patrimonio cultural se desarrolla y crece mediante reacciones empáticas que tenemos hacia personas y escenarios que existieron en el pasado.

Figura 1. Esquema circular de factores y recursos para la actractividad de las estrategias educativas patrimoniales

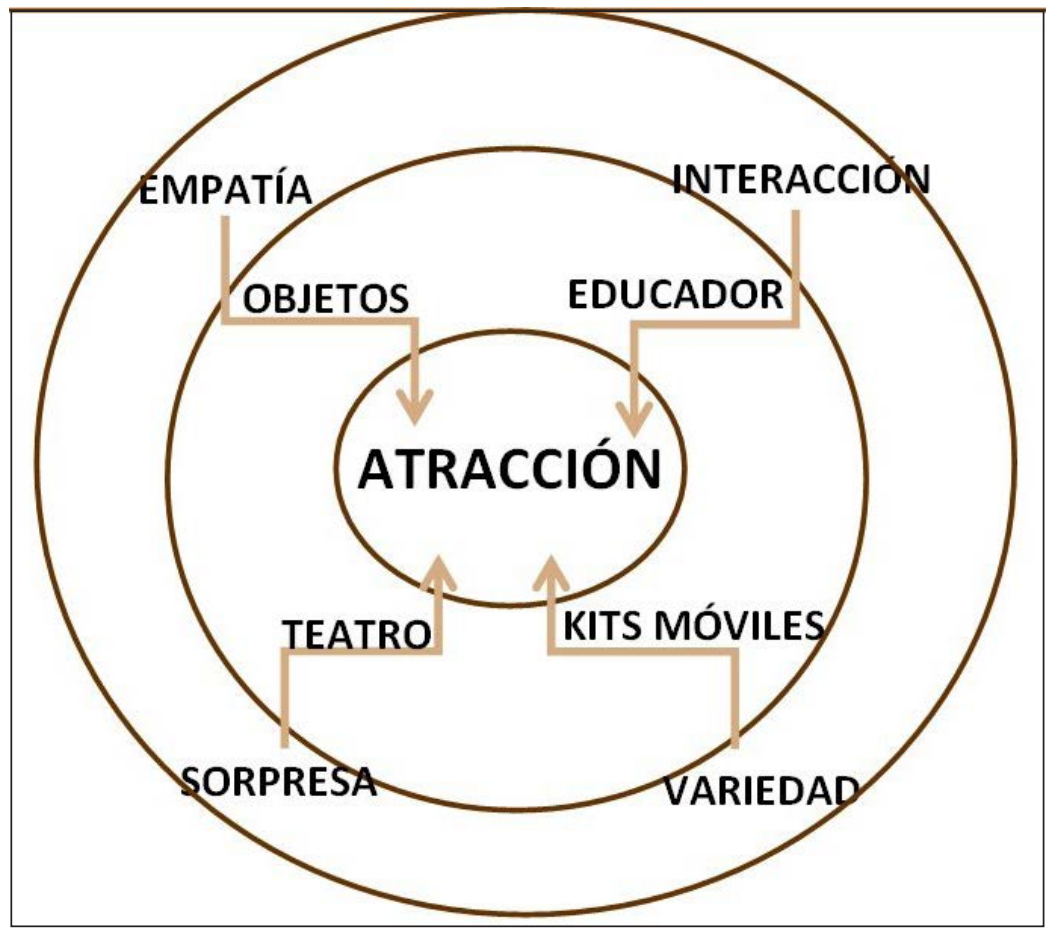

Fuente: Elaboración propia. 
En cuanto a la sorpresa, forma parte del sistema de alertas cerebrales que probablemente va unido al sistema del miedo y del pánico; de hecho, es un paso previo, con la diferencia de que la sorpresa puede desencadenar emociones negativas, con cargas de ansiedad, rabia, ira o terror, o emociones positivas, vinculadas a sentimientos de placer, de reconocimiento, de felicidad e incluso de amor (Solms y Turnbull, 2004, pp. 105-138).

Los dos factores de carácter emocional que hemos mencionado en nuestra experimentación se desencadenan a partir de fuentes primarias (documentos) que han pasado a través del tamiz del guión teatral y también a partir de los objetos contenidos en las maletas didácticas. Que el teatro es un arte que se basa sobre todo en el desencadenamiento de emociones no constituye ciertamente una novedad, pero el uso de los objetos siempre puede ser más discutible (Santacana y Llonch, 2012). Los ejemplos de emociones y situaciones empáticas desencadenadas a partir de objetos, como hemos comentado anteriormente, son muchos y podrían ejemplificarse en el relato de Dory Sontheimer (2014): una mujer barcelonesa que con motivo de la muerte de su madre descubre que la fa- llecida guardaba siete cajas de papeles y objetos que le descubrían la trágica historia de su familia, judíos alemanes que rehacen su vida en Barcelona tras sufrir la muerte de la mayor parte de los miembros de su familia. Martín en el prólogo de esta obra nos dice:

"Por favor, pongámonos por un instante en la piel de una pareja de jóvenes perseguidos a muerte y que tuvieron que cambiar de religión, de identidad y de pasado para salvar su vida y la de sus hijos pero que no pudieron proteger la vida de sus padres que terminaron en un campo de exterminio. E imaginemos después el día que decidieron guardar los objetos en cajas con la esperanza de que alguien los recuperara y reconstruyera la memoria de una familia destrozada por el nazismo. Imaginemos por lo que ha pasado Dory al descubrir los recortes y fragmentos de todo el espanto que rodeó a su familia. Hágalo, y si no se emociona es que no es de este mundo".

Por todo ello, no es exagerado concluir afirmando que existe una estrecha relación entre el factor emocional, el patrimonio y el aprendizaje de la cultura.

\section{NOTAS}

1. Véase en detalle la candidatura "Peregrinación anual al mausoleo de Sidi 'Abd el-Qader Ben Mohammed ("Sidi Cheikh") UNESCO (2013) en https://ich.unesco.org/es/RL/peregrinacion-anual-al-mausoleo-de-sidiabd-el-qader-ben-mohammed-sidicheikh-00660

\section{BIBLIOGRAFÍA}

Burillo, X., Calvera, A., Loyer, F., Mouilleseaux, J-P., Peran, M. y Rabreau, D. (1988). Historicismo y nuevas tecnologías II. En El gran arte: arquitectura (vol. 23). Barcelona: Salvat.

Choliz, M. (2005). Psicología de la emoción: El proceso emocional [en línea]. Disponible en: https://www.uv.es/=choliz

Fink, J. y Asamer, B. (1997). Die römischen Katakomben. Mainz am Rhein: Phillip von Zabern.

Goleman, D. (2008). Inteligencia emocional. Barcelona: Kairós.

Gutiérrez, J. (2011). Grupo de discusión: ¿prolongación, variación o ruptura
2. Véase en detalle la candidatura "La creación y el simbolismo de las cruces" UNESCO (2008) en https:// ich.unesco.org/es/RL/la-creaciony-el-simbolismo-de-las-cruces00013 ?RL=00013 con el focus group? Cinta Moebio, 41, pp. 105-122. https://doi.org/10.4067/ S0717-554X2011000200001

Gutterman, B. y Shalev, A. (2008). Para que lo sepan las generaciones venideras. La recordación del Holocausto en YadVashem. Jerusalen: Memorial YadVashem.

Lavallé, D., Michelet, D. y Ocampo, E. (1988). América precolombina y colonial. En El gran arte: arquitectura (vol. 4). Barcelona: Salvat.

Ledoux, J. (1999). El cerebro emocional. Barcelona: Ariel.

Martínez, T. (2014). El patrimoni religiós medieal: anàlisi, problemàtica i disseny d'estratègies didàctiques als immobles de les diòcesis catalanes. [Tesis doctoral inédita]. Universidad de Barcelona: Barcelona.

Martínez, T. y Santacana, J. (2013). La cultura museística en tiempos difíciles. Gijón: TREA.

Mora, F. (2009). Cómo funciona el cerebro. Madrid: Alianza.

Nachama, A. (ed.) (2008). Topography of terror. Berlin: Topography of Terror Foundation.

Puchta, C. y Potter, J. (2004). Focus group practice. Londres: SAGE Publications. https:// doi.org/10.4135/9781849209168 
Santacana, J. y Llonch, N. (2012). Manual de didáctica del objeto. Gijón: TREA

Santacana, J. y Llonch, N. (eds.) (2015). El patrimonio cultural inmaterial y su didáctica. Gijón: TREA.

Solms, M. y Turnbull, O. (2004). El cerebro y el mundo interior. Bogotà: Fondo de Cultura Económica.
Sontheimer, D. (2014). Las siete cajas. Barcelona: Circe.

Unesco (2013). Convención para la Salvaguardia del Patrimonio Cultural Inmaterial. [En línea]. Disponible en: http:// www.esicomos.org/Nueva_carpeta/ info_ConvenpatrilNtangESP.htm

Yerkes, R. M. y Dodson, J. D. (1908). The relation of strength of stimulus to rapidity of habit-formation. Journal of Comparative Neurology and Psychology, 18, pp. 459-482. https://doi.org/10.1002/ cne.920180503

Zanjonc, R. y Hazel, M. (1982). Affective and cognitive-factors in preferences. Journal of Consumer Research, 9 (2), pp. 123131. https://doi.org/10.1086/208905 